\title{
Valeur alimentaire et biologique de la «Gelée royale»
}

Les reclames faites dans la grande presse à propos de substances recueillies dans les ruches et servant à nourrir les futures reines, et les effets de rajeunissement que leur attribue une publicité tapageuse, ont jeté le discredit, aux yeux des médecins, sur ces produits (Apígel, Apisérum, Géloral, etc.), dont ou pouvait se demander si la suggestion n'expliquait pas le plus clair de leur efficacité un peu trop mira-culeuse. Aussi faut-il être reconnaissant à deux chercheurs de la Station d'Apiculture du Ministère français de $\Gamma$ Agriculture, R. Chau-vín et E. Lenormand, de fournir une série de documents objectifs sur ce sujet, dans un article de «Díététíque et Nutrítíon» (vol. 5, no 3, p. 19, 1956).

Les abeilles récoltent du nectar (emprunté aux glandes nectarifères de la corolle florale) dont elles feront le miel, compose presque exclu-sivement de glucose et de lévulose. Mais les larves de la ruche exigent un aliment azote: celui-ci sera fourni par le pollen des étamines, qui contient de $11 \%$ à $35 \%$ de protides ou d'acides amines.

Les pollens intéressaient jusqu'ici les médecins en tant que principe allergisant. Mais la palynologie (science des pollens) permet de distin-guer les plantes anêmophíles, dont la fécondation est assurée par le vent, et qui sont responsables du coryza spasmodique et autres affections du même genre - et les plantes entomophíles, où le pollen est transporté par des insectes, et dont le pouvoir antigénique est pra-tiquement nul.

Les pollens d'abeille sont des substances d'un richesse nutritive exceptionnelle: outre leur teneur en protides (tous les acides amines connus s'y rencontrent!), on y trouve encore jusqu'à $20 \%$ de lipides, 20 à $40 \%$ de glucides, des vitamines en quantité élevée (particulière-ment celles du groupe $\mathrm{B}$ ) et de très nombreux enzymes. Ces carac-tères concernant les pollens ordinaires, destines à assurer le déve-loppement des ouvrières, on conçoit volontiers que la «gelée royale», réservée aux futures reines, soit encore plus riche en principes de croissance, puisque les larves royales arrivent à la maturité en 13 jours, au lieu de 18 jours pour les ouvrières. D'après les analyses de -R. Ardry (Annales pharmaceutiques françaises, vol. 14, p. 97, 1956), 344

\section{Editorial}

l'extrait sec de gelée royale (soit un tiers du poids de la gelée fraîche) contient 34,9 \% de protides (6,61\% d'azote), 17,5\% de lipides, $26,4 \%$ de sucres et $2,84 \%$ de cendres minérales. Chauvin et Lenormand ont étudié Tinfluence sur la croissance d'une addition d'extrait albumineux de pollen d'abeilles à la ration alimen-taire de jeunes souris. Cette influence est indiscutable, et représente un supplement moyen de poids de $15 \%$ ou de $36 \%$ (selon qu'on ajoute une dose d'extrait correspondant à $25 \%$ ou à $50 \%$ de pollen) par rapport aux poids des témoins, avec une extreme variété (allant de 0 à $64 \%$ ) selon Гorigine du pollen considéré. D'après ces auteurs, on ne peut attribuer ce role aux vitamines, mais il s'agit plus vraisemblablement d'une action sur lesglandes endo-crines. En effet, ils notent (avec 50\% de pollen) un arrêt de croissance des organes génitaux masculins (vésicules séminales) alors que les femelles se développent normalement. De plus, les extraits de pollen provoquent une hausse 
sensible de la glycémie, dans les deux heures suivant leur ingestion. Enfin ils contiennent une principe antí-bíotíque, se traduisant pas un certain degré de «désinfection» sur la flore intestinale. Des experiences sur la jeune souris en pleine croissance ne sauraient constituer une preuve de l'efficacité d'un aliment-medicament sur $\Gamma$ bomme adulte ou vieillissant; ceux-ci reçoivent d'ailleurs, à titre thérapeutique, une dose infime du principe actif (quelques milligram mes au lieu du quart au moins de la ration nutritive). Mais il nous paraît intéressant pour les médecins de connaître la nature et les propriétés biologiques d'une substance sur laquelle ils auront parfois à exprimer une opinion réputée scientifique... $\quad$ M. D.

Seite der Therapie - Page de thérapeutique Frumusan, P., R. Cattan et M. Bucaille: Premieres tentatives chirurgicales sur le cerveau pour le traitement des ulcères gastriques et duodénaux rebelles. Sem. Hop. Paris 33, 521-533. On connaît Faction ulcérigène digestive des lesions encéphaliques: la secretion et la vascularisation de Гestomac sont contrôlées par le système neuro-végétatif et le vague en particulier. Si $\Gamma$ on admet, dans la maladie ulcéreuse spontanée, le role pathogène predominant exercé par Гinfluence nocive sur Thypothalamus d'un cortex en état de déséquilibre fonctionnel, il est logique d'essayer de soustraire les centres hypothalamiques à cette action en interrompant les voies nerveuses centripètes et centrifuges hypothalamo-corticales par $\Gamma$ électro-coagulation du cerveau préfrontal. 